\title{
Multiple Approaches to Quantifying the Effective Porosity of Lacustrine Shale Oil Reservoirs in Bohai Bay Basin, East China
}

\author{
Binyu Ma, ${ }^{1,2}$ Qinhong Hu $\mathbb{D}^{3},{ }^{3}$ Shengyu Yang $\mathbb{D}^{1,2}$ Na Yin, ${ }^{1}$ Hongguo Qiao, ${ }^{1}$ Tao Zhang, \\ and Mianmo Meng ${ }^{1}$ \\ ${ }^{1}$ Key Laboratory of Deep Oil and Gas, China University of Petroleum (East China), Qingdao 266580, China \\ ${ }^{2}$ Laboratory for Marine Mineral Resources, Qingdao National Laboratory for Marine Science and Technology, \\ Qingdao 266071, China \\ ${ }^{3}$ Department of Earth and Environment Sciences, University of Texas at Arlington, Arlington 76019, USA
}

Correspondence should be addressed to Qinhong Hu; maxhu@uta.edu and Shengyu Yang; s.yang@upc.edu

Received 2 April 2020; Revised 20 July 2020; Accepted 31 July 2020; Published 25 August 2020

Academic Editor: Jianchao Cai

Copyright (c) 2020 Binyu Ma et al. This is an open access article distributed under the Creative Commons Attribution License, which permits unrestricted use, distribution, and reproduction in any medium, provided the original work is properly cited.

\begin{abstract}
An effective porosity is defined as the ratio of volume of interconnected pore space to total volume of a porous sample. It controls the magnitude of fluid flow and is a key parameter in the assessment of recoverable resources. However, its accurate measurement in tight formations is challenging, due to their complex pore structure and lithofacies heterogeneity. In this study, porosities of sixteen lacustrine shale samples from the second Member of the Kongdian Formation $\left(\mathrm{Ek}_{2}\right)$ in the Cangdong Sag, Bohai Bay Basin were measured and compared using multiple methods and sample sizes to compare and contrast the effective porosity results. The methods included helium pycnometry (HP; cubes of $1 \mathrm{~cm}^{3}$ and grains at $500-841 \mu \mathrm{m}$ ), water immersion porosimetry (WIP; cubes), mercury intrusion porosimetry (MIP; cubes), and nuclear magnetic resonance (NMR; cubes). Finally, samples were completely sealed using paraffin for bulk density measurements to evaluate the extent of potential clay swelling in shale samples involving probing fluids. Results from the HP, WIP, and MIP methods for skeletal density, bulk density, and effective porosity with cubic samples were compared. While very similar skeletal densities were found for all three methods, a lower bulk density, and therefore lower porosity, from the MIP approach can be attributed to the experimental conditions (e.g., vacuum efficiency, applied pressure, wettability of water/helium vs. mercury) and the probable presence of pores with diameters larger than $50 \mu \mathrm{m}$ not measurable by MIP. Furthermore, the HP porosity of granular samples with $500-841 \mu \mathrm{m}$ grain sizes can be regarded as approaching the total porosity. The complicated relationship between WIP and NMR porosities may result from the heat-induced volatilization of moisture in pores during NMR tests, and countercurrent imbibition of water replacing the residual hydrocarbons during the saturation process for sample preparation in both tests. The swelling behavior of the lacustrine $\mathrm{Ek}_{2}$ shale with water is not significant because of the low content of expansive clay minerals. In summary, the WIP and HP methods are recommended for effective porosity measurement, whereas the NMR and MIP methods are invaluable for the measurement of pore-size distribution, with additional information on the effective porosity.
\end{abstract}

\section{Introduction}

The commercial exploration and production of marinesourced shale gas and oil in the United States [1-4] and marine shale gas in China $[5,6]$ has led to significant attention being paid to oil resources in lacustrine shale reservoirs in China. Examples include the Shahejie Formation in Bohai Bay Basin [7], Qingshankou Formation in Songliao Basin [8], Yanchang Formation in Ordos Basin [9], and Luocaogou
Formation in Jungar Basin [10]. However, several notable characteristics of lacustrine shales in China, such as lower thermal maturity, generation of fluids with higher viscosities and high wax contents, and limited geographical distributions, pose greater challenges to a cost-effective development compared to marine petroleum systems [11]. Thus, in addition to a direct extraction of tight oil, in situ conversion technology plays a significant role in the development of lacustrine shale oil in China [12]. An evaluation by the 
Research Institute of Petroleum Exploration and Development of PetroChina suggested that the recoverable resources of lacustrine shale oil reservoirs in China, with a thermal maturity $\left(R_{\mathrm{o}}\right)$ less than $1.0 \%$, in these areas are as large as700-900 $\times 10^{8} t$ using in situ conversion technology [13].

For either extraction approaches, a porosity measurement is important because it not only significantly affects the accuracy of resource estimates of reservoirs, but also determines favorable target areas, in conjunction with the hydrocarbon saturation and brittleness of shale reservoirs [4]. At present, porosity measurements of shale can be generally divided into the following categories: (1) gas expansion porosimetry, such as helium pycnometry (HP) for skeletal density with additional information on bulk density for calculating the porosity [14], as well as low-pressure gas physisorption with $\mathrm{N}_{2}$ or $\mathrm{CO}_{2}$ [15]; (2) three dimensional (3D) imaging techniques, such as microcomputed tomography (micro-CT), nano-CT, and focused ion beam-scanning electron microscopy (FIB-SEM) [16, 17]; (3) fluid immersion porosimetry (FIP), such as FIP with water (WIP) or kerosene (KIP) and dual liquid porosimetry (DLP), as well as mercury intrusion porosimetry (MIP) [18-22]; and (4) radiation detection methods, such as nuclear magnetic resonance (NMR) and small angle neutron scattering (SANS) [23-25]. Note that the approaches involving a probing fluid (e.g., He, $\mathrm{N}_{2}, \mathrm{CO}_{2}, \mathrm{H}_{2} \mathrm{O}$, and $\mathrm{Hg}$ ) measure the effective (or connected portion of pore space linked to sample surface) porosity, while CT, SEM, and SANS detect the total (both connected and nonconnected) porosity; in addition, gas physisorption, MIP, and NMR also quantify the pore-size (throat) distribution.

The low-pressure gas physisorption approach is usually used to characterize both macropores (>50 nm; according to the pore classification proposed by IUPAC [26]) and mesopores $(2-50 \mathrm{~nm})$ with $\mathrm{N}_{2}$, or micropores $(<2 \mathrm{~nm})$ with $\mathrm{CO}_{2}$, but this only covers a portion of the total pore space in shales, which have a broad spectrum of $\mathrm{nm}$ to $\mu \mathrm{m}$ pores [7]. The imaging approaches (nano-CT and FIB-SEM) are usually employed to observe the pore types and 3D distribution of pore networks, since the porosities from 3D reconstructions are not representative due to lower spatial resolution of micro-CT, and small scale of nano-CT and FIB-SEM analyses of heterogeneous shales [16]. Finally, the SANS approach has been recently employed to detect the volume of total (including both connected and nonconnected/isolated pores), but it is limited by sample size as well as availability of the instrumentation [25].

Kuila et al. [20] measured the porosity of shales and mudrocks using the WIP technique and concluded that measurements were reproducible with a low uncertainty, due to insignificant swelling related to the low content of smectite and mixed-layered illite-smectite (I/S) in the samples. Porosity from KIP is consistently lower than that of WIP due to incomplete pore saturation by kerosene, as the migration of kerosene is restricted by clay- and capillary-bound water in samples with a high content $(\sim 40 \%)$ of partially expandable I/S [21]. Thus, WIP is widely used in porosity measurement of shales with low contents of expandable clays, as commonly found in unconventional hydrocarbon shale reservoirs [27].
The MIP technique can obtain a range of pore structure information of shale, such as pore volume and surface area, bulk and particle densities, porosity, and pore-throat size istribution from the Washburn Equation [28]. Furthermore, Katz and Thompson's method [29] has been adopted by Gao and $\mathrm{Hu}$ [30] to obtain the permeability from MIP data. Although the MIP approach has been widely used in pore characterization of shales, some problems, such as the compressibility of shale samples at intrusion pressures higher than $10,000 \mathrm{psi}(68.9 \mathrm{MPa})$, and conformance effect from the irregularities of sample surfaces, can affect the accuracy of MIP results [31, 32]. Moreover, the existence of ink bottle pores will lead to overestimation of the contribution of smaller pores [30], but this makes MIP approach to detect pore-throat size distribution which is directly relevant to fluid flow and mass transport.

NMR refers to the response of atomic nuclei in external magnetic fields to cause resonance phenomenon [33]. Two NMR relaxations, longitudinal relaxation $\left(T_{1}\right)$ and transverse relaxation $\left(T_{2}\right)$, where $T_{2}$ is always faster than $T_{1}$, arise after the magnetization and resonance of fluid protons in porous materials [34]. Porosity of shale can be obtained by comparing $T_{2}$ signals before and after fluid saturation [24, 35]. Moreover, the NMR technique has advantages of being rapid, nondamaging to the samples, and repeatable, and therefore has been widely applied in shale reservoir studies for porosity and pore-size distribution, as well as the content and movability of oil and water [24].

All of these approaches use different-sized samples for porosity analyses, and porosities measured show a significant dependence on sample size, especially for low-porosity samples [36]. Sample crushing is needed for most of these approaches, to accelerate the intrusion of fluids (i.e., water for WIP, mercury for MIP, and helium for HP) into pore spaces and reduce the time needed for fluid saturation equilibrium [14]. However, significant discrepancies have been found from various sample sizes used in porosity measurements. Comisky et al. [37] studied the effects of sample size on porosity using the MIP method, and indicated that the effective porosity of Eagle Ford shale increased with decreasing sample sizes, because some isolated pores were opened up by the crushing process. Good agreement between MIP and HP porosities using 20-35 mesh (500-841 $\mu \mathrm{m})$ samples suggested that this sample size is optimal for shale porosity measurements [37]. Working with the Longmaxi shale in China, Sun et al. [38] suggested that sample sizes smaller than 60 mesh $(250 \mu \mathrm{m})$ may alter the integrity of the original particle size composition. Thus, in this work samples with 20-35 mesh $(500-841 \mu \mathrm{m})$ were prepared to measure the porosity using HP method, whereas cube-shaped samples $\left(\sim 1 \mathrm{~cm}^{3}\right)$ were prepared for WIP, NMR, MIP, and HP measurements. The latter were analyzed at two sample sizes so that we could assess the effect of sample size on results.

Using HP, WIP, MIP, and NMR techniques on lacustrine shale samples from the actively explored Bohai Bay Basin in East China [39], the purpose of this study was to assess the effective porosity values from multiple approaches, explain the differences in them, and evaluate the impact of 
experimental conditions and sample composition (e.g., clay swelling and organic matter contents) on these measurements.

\section{Samples and Methods}

2.1. Sample Preparation and Basic Geochemical Properties. The Paleogene-aged second Member of the Kongdian Formation $\left(\mathrm{Ek}_{2}\right)$ in the Cangdong Sag, Bohai Bay Basin, East China was deposited in a deep and semideep lacustrine environment and mainly consists of black shales and mudstones with thin dolomite and siltstone interlayers [39-41]. Sixteen shale samples were acquired from five wells: A well (4 samples), B well (4 samples), C well (6 samples), D well (1 sample), and E well (1 sample) (Figure 1). Sample IDs and their burial depths are presented in Table 1.

Each sample was processed into three different sizes for the associated tests: (1) cube-shaped samples $(\sim 1 \mathrm{~cm} \times 1 \mathrm{~cm} \times 1 \mathrm{~cm})$ for multiple porosity and density measurements; (2) granular samples with a particle size of $500-841 \mu \mathrm{m}$ for HP skeletal density measurement [14]; and (3) powdered samples with a particle size $<75 \mu \mathrm{m}$ (<\#200 mesh) for TOC (total organic carbon) and pyrolysis tests. Sample size reduction was performed by gentle crushing using a mortar and pestle, followed by stainless steel sieves under wet rinsing.

Organic matter richness and quality are always important parameters of shales, due to their significant influence on shale pore structure and reserve assessment $[3,4]$. TOC and pyrolysis analyses were performed using a LECO CS230 instrument and Rock-Eval 6 Analyzer, respectively, following established procedures [42]. The pyrolysis test provides several useful geochemical parameters, such as thermally extractable hydrocarbon content $\left(S_{1}\right)$, maturity $\left(T_{\max }\right)$, and remaining hydrocarbon potential $\left(S_{2}\right)$. The hydrogen index $(\mathrm{HI})$ is calculated as $100 \times S_{2} /$ TOC.

2.2. HP Measurement. The Gas Research Institute (GRI) method developed by Luffel and Guldry [14] has been widely employed in porosity and permeability measurements of the shale matrix. Combining bulk density of intact (i.e., cubic) samples (e.g., measured by mercury immersion using Archimedes' Principle), and skeletal density of granular samples $(500-841 \mu \mathrm{m})$ measured by HP after crushing and then solvent extraction and followed by drying in an oven, the GRI porosity can be calculated as follows:

$$
\phi_{\mathrm{GRI}}=\frac{\rho_{\mathrm{s}-\text { Granular sample }}-\rho_{\mathrm{b}-\text { Intact sample }}}{\rho_{\mathrm{s}-\text { Granular sample }}} \times 100 .
$$

However, there are potential sources of errors in the GRI procedure, such as an artificial increase in porosity by removing some organic matter during solvent extraction and different choices of drying temperatures $\left(60^{\circ} \mathrm{C}, 105^{\circ} \mathrm{C}\right.$, or $200^{\circ} \mathrm{C}$ ) [20]. In this study, two sample types, namely $\sim 10 \mathrm{~g}$ granular and cube-shaped samples, were first oven-dried at $60^{\circ} \mathrm{C}$ for $48 \mathrm{~h}$ to evaluate the effective (instead of total [12]) porosity, and then cooled to about $23^{\circ} \mathrm{C}$ in a desiccator. Samples were not solvent extracted. The samples were then analyzed for skeletal density using the HP technique with a G-DenPyc
2900 instrument. Then, the HP porosity ( $\phi_{\mathrm{HP}-\mathrm{GRI}}$ for granular samples or $\phi_{\mathrm{HP}-\mathrm{Cube}}$ for cube-shaped samples) was calculated using equation (2) and the bulk density (from the WIP test):

$$
\phi_{\mathrm{HP}-\mathrm{GRI}}\left(\text { or } \phi_{\mathrm{HP}-\mathrm{Cube}}\right)=\frac{\rho_{\mathrm{s}-\mathrm{GRI}}\left(\text { or } \rho_{\mathrm{s}-\mathrm{Cube}}\right)-\rho_{\mathrm{b}-\mathrm{WIP}}}{\rho_{\mathrm{s}-\mathrm{GRI}}\left(\text { or } \rho_{\mathrm{s}-\text { Cube }}\right)} \times 100 \text {. }
$$

2.3. WIP Measurement. For cubic samples, the bulk density, skeletal density, and porosity were determined by saturating samples with a liquid (deionized (DI) water) and calculating the pore volume from the weight difference between the dry and fully-saturated (assisted with vacuum pulling) samples, followed by bulk volume determination using Archimedes' Principle [20]. This technique is called water immersion porosimetry (WIP) when DI water is used as the saturation fluid.

In this study, $1 \mathrm{~cm}$ sided cubes saw-cut from each sample were polished with 2000-grit sandpaper to smooth out surface roughness (the measured roughness is reduced from $1.26 \pm 0.025 \mu \mathrm{m}$ for saw-cut samples to $\sim 0.2 \mu \mathrm{m}$ ) which would otherwise increase the uncertainty of the results. The smooth samples were first oven dried at $60^{\circ} \mathrm{C}$ for $48 \mathrm{~h}$ to remove the moisture and volatile hydrocarbons in the pore space without influencing the clay-bound water and destroying the structure of clay minerals [43]. The weight of dry samples in air $\left(\mathrm{DW}_{\mathrm{Air}}\right)$ was measured using a Radwag AS 82/220.R2 (readability $0.01 \mathrm{mg}$ ). Using a custom-designed saturation apparatus, the samples were evacuated under a vacuum of $\sim 200 \mathrm{~Pa}$ for $15 \mathrm{~h}$ inside the saturator and then were saturated with DI water under $15 \mathrm{MPa}$ pressure for $24 \mathrm{~h}$. Subsequently, the weight of the saturated sample in air $\left(\mathrm{SW}_{\text {Air }}\right)$, after removing the excess surface water with a slightly damp Kimwipe, was obtained, along with the submerged weight of the saturated sample in DI water $\left(\mathrm{SW}_{\mathrm{Sub}}\right)$.

The bulk and skeletal densities of the sample were calculated from Equations (3) and (4).

$$
\begin{gathered}
\rho_{\mathrm{b}-\mathrm{WIP}}=\frac{\mathrm{DW}_{\mathrm{Air}}}{\mathrm{SW}_{\mathrm{Air}}-\mathrm{SW}_{\mathrm{Sub}}} \times \rho_{\mathrm{H}_{2} \mathrm{O}}, \\
\rho_{\text {s-WIP }}=\frac{\mathrm{DW}_{\mathrm{Air}}}{\mathrm{DW}_{\mathrm{Air}}-\mathrm{SW}_{\mathrm{Sub}}} \times \rho_{\mathrm{H}_{2} \mathrm{O}},
\end{gathered}
$$

where $\rho_{\mathrm{H}_{2} \mathrm{O}}$ is the density of DI water at the experimental temperature (around $23^{\circ} \mathrm{C}$ ). Following Haynes et al. [44], $\rho_{\mathrm{H}_{2} \mathrm{O}}$ is calculated using equation (5) as a function of temperature, which does not vary much:

$$
\rho_{\mathrm{H}_{2} \mathrm{O}}=-0.0000053 T^{2}+0.0000081 T+1.0001627 \text {, }
$$

where $T$ is the temperature of DI water. The porosity $\left(\phi_{\text {WIP }}\right)$ of the sample measured by the WIP technique is then calculated using equation (6):

$$
\phi_{\mathrm{WIP}}=\frac{\rho_{\mathrm{s}-\mathrm{WIP}}-\rho_{\mathrm{b}-\mathrm{WIP}}}{\rho_{\mathrm{s}-\mathrm{WIP}}} \times 100 .
$$




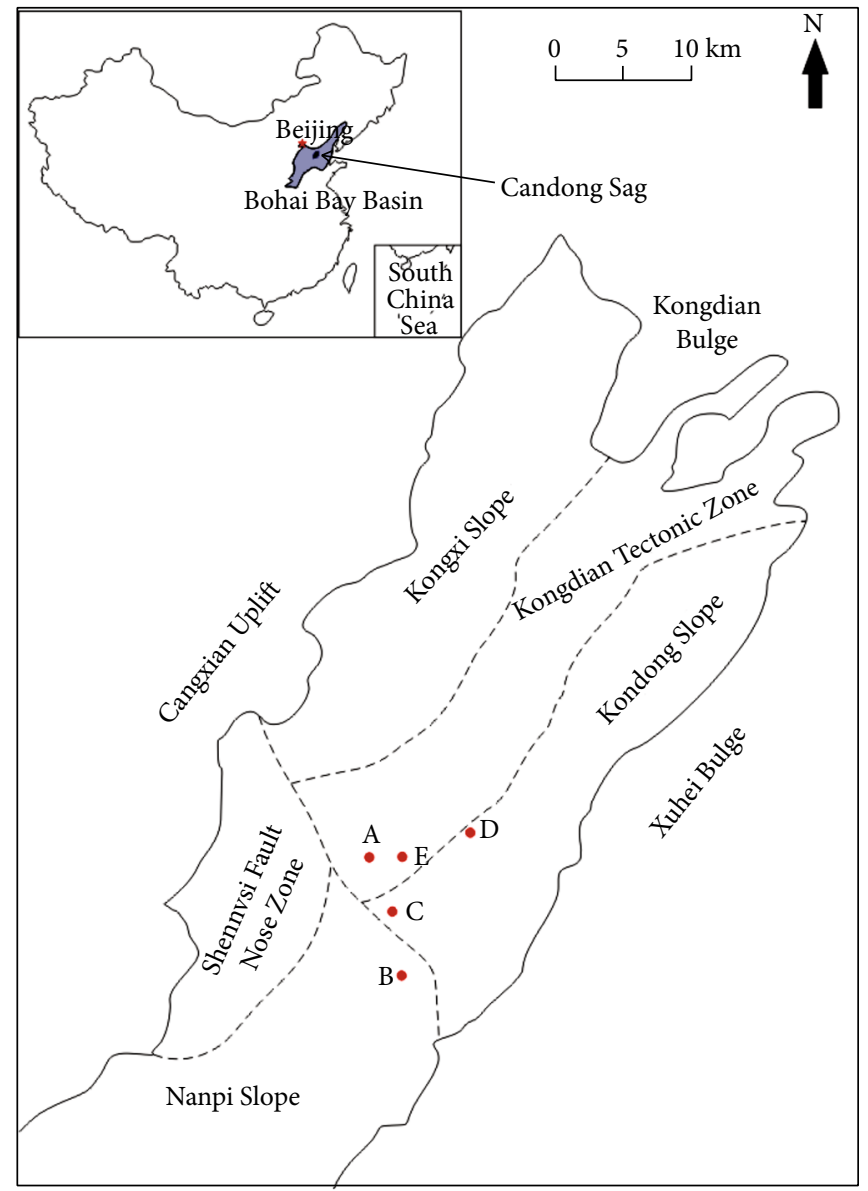

$\bullet$ Wells

Tectonic unit boundary

Figure 1: Map of Cangdong Sag in Bohai Bay Basin and location of five sampling wells (modified from [41]).

2.4. MIP Measurement. MIP analysis is one of the most efficient methods to characterize pore structure for a wide range of porous media $[7,22,45]$, because mercury has a high surface energy and is nonwetting. Liquid mercury is injected with a progressively increasing external pressure into the pore networks by incrementally overcoming the capillary pressure. Assuming that pores are cylindrical in shape, the relationship between applied pressure and the pore-throat size can be described using the Washburn equation [27]. The incremental mercury intrusion volume is monitored at each applied pressure to obtain the cumulative pore volume. Combining the pore volume and sample volume, which is obtained by subtracting the mercury volume at a low applied pressure (just to envelop the sample surface, without mercury intrusion into the pore space, to obtain the bulk volume) from the volume of the penetrometer when empty, the porosity $\left(\phi_{\text {MIP }}\right)$ can be calculated. Then, the bulk density $\left(\rho_{\mathrm{b}-\mathrm{MIP}}\right)$ and skeletal density $\left(\rho_{\text {s-MIP }}\right)$ can be calculated from mercury weight (volume) at the beginning and end of MIP tests.

Before the MIP experiments, each smooth cube-shaped sample was oven dried at $60^{\circ} \mathrm{C}$ for at least $48 \mathrm{~h}$. A Micromeri- tics AutoPore IV 9520 was utilized to measure porosity and pore-throat size distribution (not a focus of this work) under the intrusion pressures from 5 psi $(0.034 \mathrm{MPa})$ to $60,000 \mathrm{psi}(413 \mathrm{MPa})$, corresponding to pore-throat sizes from $50 \mu \mathrm{m}$ to $2.8 \mathrm{~nm}$ using the modified Washburn equation of considering both the variable contact angle and surface tension of mercury in nm-sized pore throats [46]. At the beginning of the MIP tests, the samples were evacuated to $50 \mu \mathrm{m} \mathrm{Hg}$ pressure $(6.7 \mathrm{~Pa})$, and an equilibration time of $60 \mathrm{~s}$ was selected at each applied pressure point. The skeletal density obtained from the MIP measurement was used to compare with the same data from WIP and HP methods.

2.5. NMR Measurement. Porosity can be calculated from the $\mathrm{T}_{2}$ spectrum in NMR tests, as the amplitude of $T_{2}$ is proportional to the number of hydrogen atoms, which is in turn used to determine the fluid (i.e., pore) volume within a sample [24]. In this study, the $T_{2}$ spectrum was measured successively in dry and water saturated samples using a MesoMR23-060H-I, NIUMAG Corporation. The porosity 
was calculated based on the $\triangle T_{2}$ between dry and saturated samples, to remove the influence of background signals from the presence of hydrogen-containing organic matter, claybound water, and structural water in shale [24]. The saturated sample was analyzed by NMR after the WIP measurement on that sample, which provides the bulk volume needed in the calculation of porosity from NMR data. In this work, the NMR experimental parameters were as follows: echo interval TE, $0.1 \mathrm{~ms}$; waiting time TW, $3000 \mathrm{~ms}$; number of scans, 32 times; number of echoes, 6000 times.

2.6. Bulk Density Measurements from Sample Envelopment. In addition to the abovementioned methods, the bulk density of a sample can be measured using Archimedes' Principle after being totally sealed by a nonwetting material such as paraffin (following the Chinese National Standard GB/T 23561.3-2009) [47]. The cube-shaped samples were used to measure bulk density by this method after NMR measurement. Firstly, the air-dry sample was weighed in air $\left(W_{\text {Sample }}\right)$. Then paraffin, with a measured density $\left(\rho_{\text {Paraffin }}\right)$ of $0.9225 \mathrm{~cm}^{3} / \mathrm{g}$, was employed to seal the sample. After that, the sample with paraffin was weighed in air $\left(W_{\text {Sample+Paraffin }}\right)$ and in DI water $\left(\mathrm{SW}_{\text {Sample+Paraffin }}\right)$. Finally, the bulk density of the sample ( $\left.\rho_{\text {b-Paraffin-sealing }}\right)$ can be determined from equation. (7).

$$
\rho_{\mathrm{b}-\text { Paraffin-sealing }}=\frac{W_{\text {Sample }}}{\left(W_{\text {Sample+Paraffin }}-\mathrm{SW}_{\text {Sample+Paraffin }}\right) / \rho_{\mathrm{H}_{2} \mathrm{O}}-\left(W_{\text {Sample+Paraffin }}-W_{\text {Sample }}\right) / \rho_{\text {Paraffin }}} .
$$

Furthermore, a Micromeritics GeoPyc 1365 instrument was employed to measure the bulk density of oven-dried cubic samples with $\sim 100 \mu \mathrm{m}$ diameter DryFlo ${ }^{\circledR}$ as the enveloping material [48]. The result can be compared with the results of the WIP and paraffin-sealing methods to evaluate the extent of swelling on shale samples from contact with water in WIP tests. To verify the effect of clay minerals, especially expandable smectite and mixed-layered illite-smectite, on sample swelling, the quantitative abundance of clay minerals was obtained by X-ray diffraction (XRD) analyses using powdered sample $(<75 \mu \mathrm{m})$.

\section{Results}

3.1. Total Organic Carbon (TOC) and Pyrolysis and Clay Minerals. TOC and pyrolysis data are given in Table 1. TOC values range from 0.44 to $8.20 \mathrm{wt} . \%$, with an average of 2.93 wt.\% and standard deviation of 1.98 wt.\%. Most samples are organic-rich with TOC contents greater than $2 \mathrm{wt} . \%$. The $S_{1}$ values obtained from pyrolysis tests range from 0.23 to $4.52 \mathrm{mg} \mathrm{HC/g}$ rock, with an average of 2.19 and standard deviation of $1.44 \mathrm{mg} \mathrm{HC/g}$ rock. HI values range from 109 to 681 . All samples except for three have TOC $>1.5 \%$ and $\mathrm{HI}>300$, suggesting they are good oil-prone source rocks. Two samples have TOC $<0.5 \%$ and $\mathrm{HI}<150$, suggesting they are and always were poor source rocks. The $T_{\max }$ ranges from 442 to $450^{\circ} \mathrm{C}$, indicating the samples are mature for oil generation, which is consistent with other studies $[39,40]$.

The clay mineral contents range from 3 to $45 \%(N=16)$, with a mean value of $21 \%$ (Table 1 ). The relative concentrations of mixed-layered illite-smectite to total clay minerals average $41 \%$ and range between 7 to $82 \%$, and the smectite contents range from 2 to $47 \%$, with the values below detection for almost half of 16 samples.

\subsection{Sample Densities}

3.2.1. Bulk Density from WIP, Paraffin-Sealing, and DryFloEnvelopment Methods. As shown in Table 2, the bulk density values obtained from WIP tests range from 2.060 to $2.538 \mathrm{~g} / \mathrm{cm}^{3} \quad\left(2.425 \pm 0.119 \mathrm{~g} / \mathrm{cm}^{3} ; \quad\right.$ average \pm standard deviation), very close to these from the paraffin-sealing method at 2.070 to $2.549 \mathrm{~g} / \mathrm{cm}^{3}\left(2.445 \pm 0.122 \mathrm{~g} / \mathrm{cm}^{3}\right)$. A comparison of results for 16 samples from these two methods is shown in Figure 2, in which the bulk density of WIP measurement is similar to or smaller than that of samples sealed by paraffin. The relative difference in bulk density between the WIP and paraffin-sealing methods ranges from 0.125 to $1.47 \%$; sample B-3834 has the highest relative difference of $3.10 \%$. The results for five samples from DryFlo ${ }^{\circledR}$ envelopment are also shown in Table 2, and the comparison with WIP results is shown in Figure 2. The results with DryFlo ${ }^{\circledR}$ are slightly larger than those of WIP tests, with the range of relative difference from 0.14 to $1.40 \%$.

3.2.2. Skeletal Density from HP, WIP, and MIP Methods. Skeletal density of cube-shaped samples was obtained from WIP, MIP, and HP measurements, whilst the HP test was also conducted on granular samples. Skeletal densities from these methods are shown in Table 2. The skeletal density of granular samples from $\mathrm{HP}$ ranges from 2.242 to $2.648 \mathrm{~g} / \mathrm{cm}^{3}\left(2.550 \pm 0.093 \mathrm{~g} / \mathrm{cm}^{3}\right)$, which is systematically larger than the results of all other measurements (Table 2; Figure 3). The results from WIP range from 2.175 to $2.629 \mathrm{~g} / \mathrm{cm}^{3}\left(2.515 \pm 0.106 \mathrm{~g} / \mathrm{cm}^{3}\right)$, whereas the skeletal density from MIP ranges from 2.187 to $2.608 \mathrm{~g} / \mathrm{cm}^{3}$ $\left(2.517 \pm 0.100 \mathrm{~g} / \mathrm{cm}^{3}\right)$. Figure 3 shows the comparison of skeletal density results from WIP and MIP measurements (blue circles), which is seen clustering around the 1:1 line. A slight increase in HP densities of almost all cube-shaped samples compared with these of WIP tests is also shown in Figure 3 (red diamonds).

3.3. Effective Porosity of the Samples. Four different methods (HP, WIP, MIP, and NMR) were employed to measure the effective porosity of cube-shaped samples, and the results 
TABLE 1: Basic information of $\mathrm{Ek}_{2}$ samples employed in this study.

\begin{tabular}{|c|c|c|c|c|c|c|c|c|c|c|}
\hline Sample & $\begin{array}{l}\text { Depth } \\
\text { (m) }\end{array}$ & $\begin{array}{c}\text { TOC } \\
(\%)\end{array}$ & $\begin{array}{c}S_{1} \\
(\mathrm{mg} / \mathrm{g})\end{array}$ & $\begin{array}{c}S_{2} \\
(\mathrm{mg} / \mathrm{g})\end{array}$ & $\begin{array}{l}T_{\max } \\
\left({ }^{\circ} \mathrm{C}\right)\end{array}$ & $\begin{array}{c}\mathrm{HI} \\
(\mathrm{mg} / \mathrm{g})\end{array}$ & $\begin{array}{c}\text { Total clays } \\
(\%)\end{array}$ & $\begin{array}{c}\text { Smectite } \\
(\%)\end{array}$ & $\begin{array}{l}\text { Illite } \\
(\%)\end{array}$ & $\begin{array}{c}\text { Mixed-layered illite-smectite } \\
(\%)\end{array}$ \\
\hline A-3143 & 3143.87 & 2.49 & 1.28 & 18.08 & 443 & 726 & 20.64 & 33 & 22 & 22 \\
\hline A-3150 & 3150.23 & 1.66 & 0.81 & 9.68 & 442 & 583 & 12.41 & 5 & 22 & 59 \\
\hline A-3161 & 3161.47 & 1.56 & 0.54 & 9.62 & 444 & 617 & 20.23 & & 13 & 82 \\
\hline A-3268 & 3268.09 & 6.44 & 2.61 & 43.83 & 446 & 681 & 44.75 & & 13 & 80 \\
\hline B-3831 & 3831.92 & 0.48 & 0.29 & 0.59 & 445 & 123 & 43.70 & 2 & 24 & 44 \\
\hline B-3834 & 3834.15 & 0.44 & 0.23 & 0.48 & 450 & 109 & 32.34 & 2 & 27 & 41 \\
\hline B-3847 & 3847.25 & 2.79 & 3.93 & 10.81 & 446 & 387 & 17.82 & & 21 & 10 \\
\hline B-3859 & 3859.39 & 4.72 & 3.87 & 22.73 & 446 & 482 & 9.90 & 37 & 5 & 19 \\
\hline C-4081 & 4081.55 & 2.6 & 3.39 & 14.55 & 450 & 560 & 12.51 & & 44 & 51 \\
\hline C-4095 & 4095.27 & 1.79 & 4.52 & 6.67 & 442 & 373 & 16.05 & 32 & 20 & 13 \\
\hline C-4096 & 4096.66 & 2.02 & 4.02 & 8.46 & 443 & 419 & 13.99 & & 20 & 77 \\
\hline C-4113 & 4113.26 & 2.2 & 1.6 & 9.33 & 447 & 424 & 13.51 & 20 & 21 & 1 \\
\hline C-4116 & 4116.29 & 3.37 & 3.03 & 8.01 & 443 & 238 & 3.36 & 10 & 20 & 18 \\
\hline C-4126 & 4126.07 & 2.4 & 2.47 & 9.11 & 445 & 380 & 11.77 & & 21 & 75 \\
\hline D-2916 & 2916.19 & 3.7 & 0.45 & 21.15 & 443 & 572 & 33.90 & 47 & 3 & 25 \\
\hline E-2603 & 2603.31 & 8.2 & 1.94 & 53.76 & 446 & 656 & 34.91 & & 13 & 39 \\
\hline
\end{tabular}

TABLE 2: Results of bulk and skeletal densities from various methods.

\begin{tabular}{|c|c|c|c|c|c|c|c|}
\hline \multirow[b]{2}{*}{ Sample } & \multicolumn{2}{|c|}{ HP } & \multicolumn{2}{|c|}{ WIP } & \multirow{2}{*}{$\begin{array}{c}\text { MIP } \\
\text { Skeletal density } \\
\left(\mathrm{g} / \mathrm{cm}^{3}\right)\end{array}$} & \multirow{2}{*}{$\begin{array}{c}\text { Sealed by } \\
\text { paraffin } \\
\text { Bulk density } \\
\left(\mathrm{g} / \mathrm{cm}^{3}\right)\end{array}$} & \multirow{2}{*}{$\begin{array}{c}\text { Enveloped by } \\
\text { DryFlo } \\
\text { Bulk density } \\
\left(\mathrm{g} / \mathrm{cm}^{3}\right)\end{array}$} \\
\hline & $\begin{array}{l}\text { Skeletal density } \\
\qquad\left(\mathrm{g} / \mathrm{cm}^{3}\right)\end{array}$ & $\begin{array}{l}\text { Skeletal density } \\
\left(\mathrm{g} / \mathrm{cm}^{3}\right)\end{array}$ & $\begin{array}{l}\text { Bulk density } \\
\left(\mathrm{g} / \mathrm{cm}^{3}\right)\end{array}$ & $\begin{array}{l}\text { Skeletal density } \\
\left(\mathrm{g} / \mathrm{cm}^{3}\right)\end{array}$ & & & \\
\hline A-3143 & $2.514 \pm 0.002$ & $2.552 \pm 0.004$ & $2.404 \pm 0.012$ & $2.491 \pm 0.008$ & 2.510 & 2.412 & \\
\hline A-3150 & $2.587 \pm 0.003$ & $2.594 \pm 0.004$ & $2.457 \pm 0.018$ & $2.585 \pm 0.016$ & 2.575 & 2.486 & 2.463 \\
\hline A-3161 & $2.595 \pm 0.002$ & $2.619 \pm 0.004$ & $2.454 \pm 0.002$ & $2.590 \pm 0.002$ & 2.565 & 2.451 & 2.489 \\
\hline A-3268 & $2.383 \pm 0.002$ & $2.435 \pm 0.003$ & $2.265 \pm 0.001$ & $2.381 \pm 0.001$ & 2.424 & 2.282 & \\
\hline B-3831 & $2.624 \pm 0.007$ & $2.648 \pm 0.006$ & $2.473 \pm 0.003$ & $2.629 \pm 0.004$ & 2.589 & 2.500 & \\
\hline B-3834 & $2.583 \pm 0.005$ & $2.598 \pm 0.005$ & $2.449 \pm 0.004$ & $2.586 \pm 0.003$ & 2.517 & 2.528 & \\
\hline B-3847 & $2.526 \pm 0.009$ & $2.547 \pm 0.009$ & $2.465 \pm 0.025$ & $2.506 \pm 0.022$ & 2.534 & 2.489 & 2.469 \\
\hline B-3859 & $2.501 \pm 0.008$ & $2.544 \pm 0.008$ & $2.420 \pm 0.015$ & $2.498 \pm 0.016$ & 2.502 & 2.440 & 2.454 \\
\hline C-4081 & $2.528 \pm 0.002$ & $2.549 \pm 0.011$ & $2.477 \pm 0.009$ & $2.526 \pm 0.008$ & 2.514 & 2.499 & \\
\hline C-4095 & $2.593 \pm 0.005$ & $2.605 \pm 0.005$ & $2.525 \pm 0.004$ & $2.591 \pm 0.002$ & 2.600 & 2.537 & \\
\hline C-4096 & $2.532 \pm 0.004$ & $2.545 \pm 0.009$ & $2.463 \pm 0.006$ & $2.528 \pm 0.012$ & 2.580 & 2.499 & \\
\hline C-4113 & $2.568 \pm 0.007$ & $2.578 \pm 0.006$ & $2.513 \pm 0.009$ & $2.566 \pm 0.016$ & 2.576 & 2.521 & \\
\hline C-4116 & $2.571 \pm 0.006$ & $2.618 \pm 0.007$ & $2.538 \pm 0.001$ & $2.566 \pm 0.002$ & 2.608 & 2.543 & \\
\hline C-4126 & $2.555 \pm 0.004$ & $2.605 \pm 0.008$ & $2.526 \pm 0.004$ & $2.563 \pm 0.001$ & 2.559 & 2.549 & 2.543 \\
\hline D-2916 & $2.468 \pm 0.008$ & $2.513 \pm 0.004$ & $2.305 \pm 0.002$ & $2.457 \pm 0.007$ & 2.433 & 2.316 & \\
\hline E-2603 & $2.177 \pm 0.002$ & $2.242 \pm 0.010$ & $2.060 \pm 0.026$ & $2.175 \pm 0.028$ & 2.187 & 2.070 & \\
\hline
\end{tabular}

${ }^{1}$ Data for granular samples; all other data are for cubic samples.

are shown in Table 3 . The effective porosity of cube-shaped samples from HP tests, calculated using HP-derived skeletal density and WIP bulk density, ranges from 1.13 to $6.62 \%$. The effective porosity of samples from WIP ranges from 1.10 to $6.20 \%$, whereas the effective porosity from MIP and NMR measurements ranges from 0.41 to $3.55 \%$ and from 1.88 to $4.04 \%$, respectively. In addition, the HP measurement were also conducted on granular samples, and the results range from 2.52 to $8.30 \%$ (Table 3 ). The values of $\mathrm{HP}$ porosity $(4.93 \pm 1.91 \%)$ of the granular samples are the highest, in a decreasing order followed by the porosity values for cubes measured by HP $(3.77 \pm 1.69 \%)$, WIP $(3.60 \pm 1.70 \%)$, NMR porosity $(2.86 \pm 0.56 \%)$, and MIP $(2.05 \% \pm 0.92 \%)$ (Table 3; Figure 4$)$. 


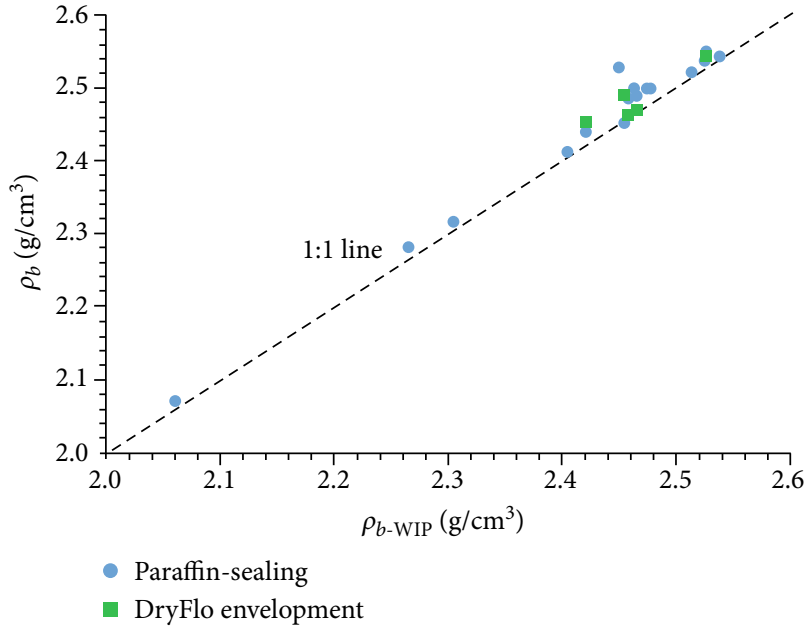

FIGURE 2: Comparison of bulk density measured from the WIP, paraffin-sealing, and DryFlo-enveloping techniques; the $x$-axis is for bulk density from the WIP method, and the $y$-axis from the paraffin-sealing and DryFlo-enveloping methods. The WIP bulk density is smaller than the other methods when the point is located above the $1: 1$ line.

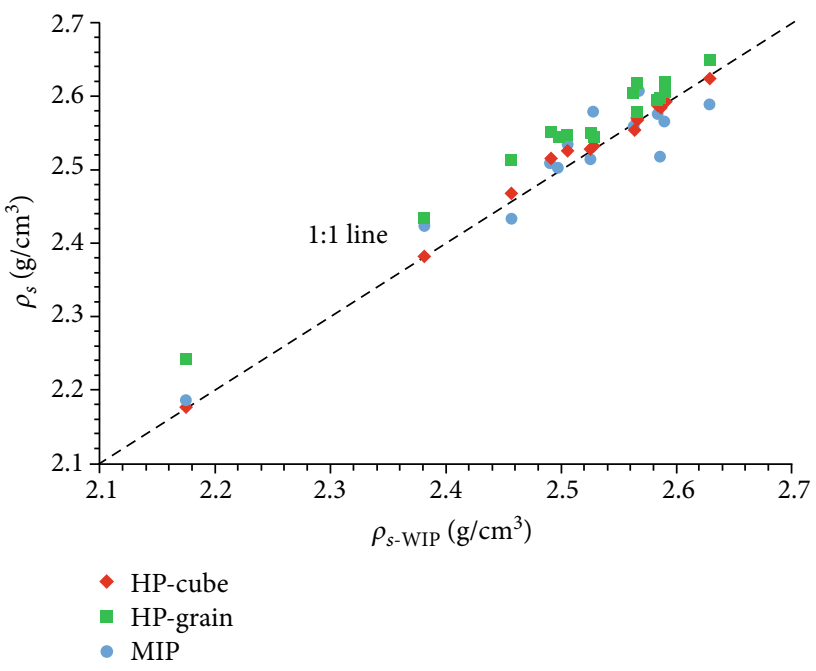

Figure 3: Comparison of skeletal density measured from the HP, WIP, and MIP techniques; the $x$-axis presents skeletal density from the WIP method and the $y$-axis from the HP and MIP methods, with smaller values from WIP than from the other methods indicated by the data located above the $1: 1$ line.

\section{Discussion}

4.1. WIP and NMR Methods Employing Water as the Probing Fluid. Shale is a unique hydrocarbon reservoir due to its pronounced heterogeneity with comingling composition such as organic matter and inorganic matrices [3, 4]. The same sample cubes were employed to measure the NMR porosity following the WIP measurement, to minimize the impact of shale heterogeneity when cutting $\sim 1 \mathrm{~cm}^{3}$ sized cubes. Equally importantly, WIP provides the sample bulk volume to go with the calculation of porosity from NMR analyses. The
TABLE 3: Results of effective porosity from four methods.

\begin{tabular}{lccccc}
\hline Sample & $\begin{array}{c}\text { HP porosity } \\
(\%)\end{array}$ & $\begin{array}{c}\text { WIP } \\
\text { porosity (\%) }\end{array}$ & $\begin{array}{c}\text { MIP } \\
\text { porosity (\%) }\end{array}$ & $\begin{array}{c}\text { NMR } \\
\text { porosity (\%) }\end{array}$ \\
& Cube & GRI & & & \\
\hline A-3143 & 4.357 & 5.776 & 3.480 & 0.917 & 2.697 \\
A-3150 & 5.025 & 5.266 & 4.920 & 2.134 & 3.131 \\
A-3161 & 5.422 & 6.288 & 5.224 & 2.696 & 3.363 \\
A-3268 & 4.957 & 6.987 & 4.896 & 2.532 & 3.083 \\
B-3831 & 5.737 & 6.607 & 5.916 & 2.790 & 3.406 \\
B-3834 & 5.178 & 5.714 & 5.302 & 2.806 & 2.915 \\
B-3847 & 2.398 & 3.187 & 1.603 & 2.750 & 1.957 \\
B-3859 & 3.221 & 4.870 & 3.091 & 2.590 & 2.986 \\
C-4081 & 2.025 & 2.847 & 1.944 & 1.067 & 2.812 \\
C-4095 & 2.636 & 3.084 & 2.549 & 0.742 & 3.098 \\
C-4096 & 2.737 & 3.234 & 2.595 & 2.910 & 2.572 \\
C-4113 & 2.144 & 2.523 & 2.084 & 1.363 & 1.875 \\
C-4116 & 1.291 & 3.055 & 1.097 & 1.109 & 2.194 \\
C-4126 & 1.128 & 3.043 & 1.448 & 0.406 & 2.327 \\
D-2916 & 6.623 & 8.295 & 6.198 & 2.402 & 4.042 \\
E-2603 & 5.367 & 8.109 & 5.276 & 3.549 & 3.333 \\
\hline
\end{tabular}

comparison between WIP and NMR effective porosity is shown in Figure 5, and three regions can be divided and marked according to the porosity range. In Region I with WIP porosity $<2 \%$, the NMR porosity is generally greater than the WIP porosity. This is the opposite of Region III, in which the WIP porosity is greater than the NMR porosity for WIP porosities greater than $4 \%$. In the intermediate region, data plot on or close to the $1: 1$ line.

The difference between WIP and NMR porosities is probably due to an increase in experimental temperature inside the sample container during the analysis by NMR, which takes $\sim 5 \mathrm{~min}$ for each sample analysis, that could result in a heat-induced loss of moisture in the samples, especially in macropores near the surfaces of the samples. In addition, a countercurrent imbibition may occur during the vacuum saturation process to displace some residual hydrocarbons from the as-received (i.e., not solvent cleaned) shale samples [49-51]; however, this will influence both the WIP and NMR results. Imbibition may influence the WIP results because the density of hydrocarbons $\left(0.86 \sim 0.89 \mathrm{~g} / \mathrm{cm}^{3}\right.$ at $\left.20^{\circ} \mathrm{C}\right)$ from $\mathrm{Ek}_{2}$ shale reservoir is less than $0.998 \mathrm{~g} / \mathrm{cm}^{3}$ of DI water [39]. However, the heating pretreatment of samples may potentially result in an increase of density of residual hydrocarbons by removing some lighter components that would reduce the influence of imbibition on WIP results; it is reported that shale oil produced from the $\mathrm{Ek}_{2}$ Formation has a high content of asphaltenes at $16-76 \%$, with an average of 39\% [52]. Thus, the values of difference in hydrogen index between residual hydrocarbons and DI water is quite higher than the values of density difference between hydrocarbons and DI water. Therefore, the imbibition may have greater influence on NMR porosity, especially the samples with lower porosity (e.g., Region I), in which the high proportion of small pores with large capillary forces may have a stronger imbibition effect [53]. 


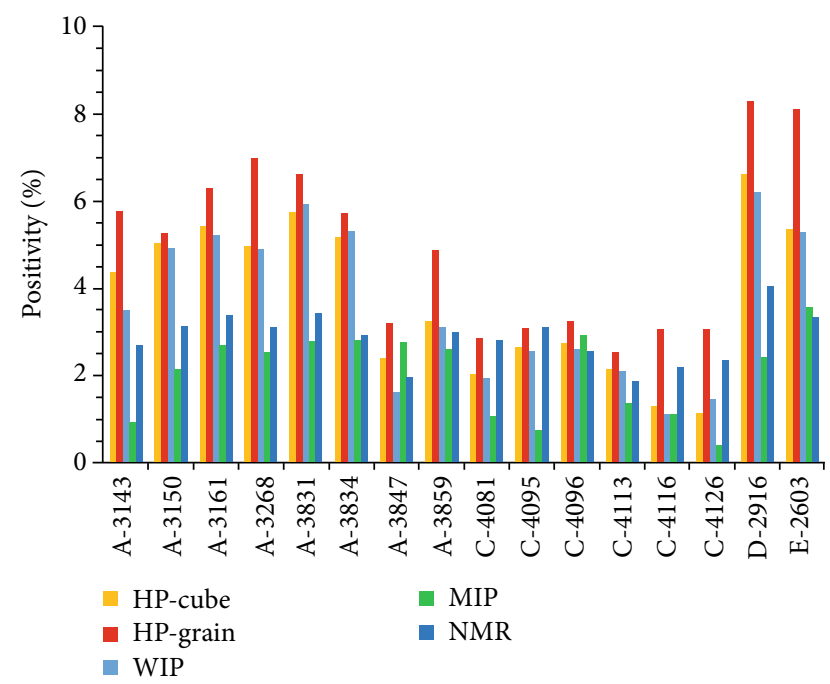

FIGURE 4: Histogram comparison of porosities from the four different methods for each sample.

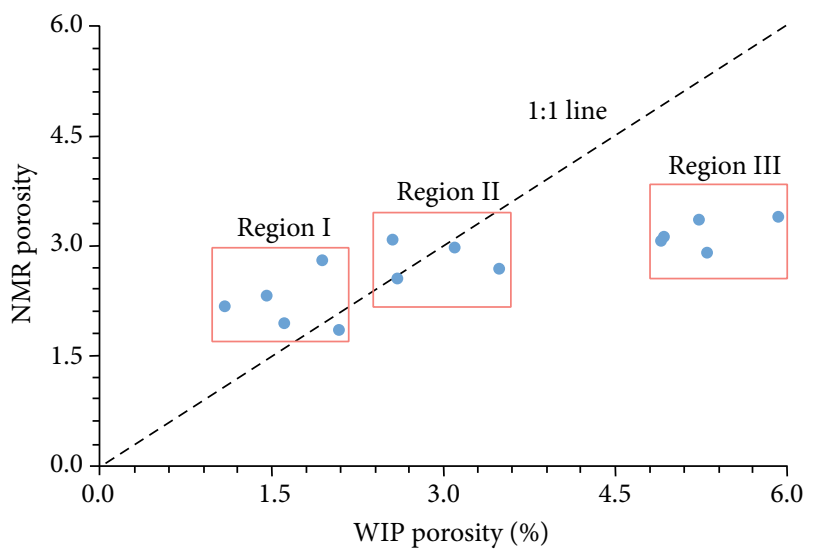

FIgURE 5: Comparison of porosities from WIP and NMR measurements. Three regions are divided according to absolute difference between porosities from two methods.

Furthermore, the experimental parameters play an extremely critical role in NMR measurements. In previous studies of shale samples, the echo interval TE usually ranges from 0.06 to $0.2 \mathrm{~ms}$ [24], and a shorter echo interval TE may potentially cause an enhancement of the $T_{2}$ spectrum amplitude of small pores but a reduction for large pores. In contrast, longer echo interval TE would lose some signals of small pores and cause a lower value of NMR porosity [24]. The porosity may be potentially underestimated by NMR due to the wide pore-size range of $\mathrm{Ek}_{2}$ shale samples, in which abundant inorganic and organic pores are protected by a high proportion of brittle minerals from compaction [39]. In addition, a shorter waiting time TW may result in nonmagnetization of some of the atomic nuclei of fluids in large pores and therefore less detection of large pores. At the same time, the number of scans may cause varying results depending on the strength of resonance signals. Overall, in this study using the same cubic samples, we modified the parameters of waiting time TW and number of scans to

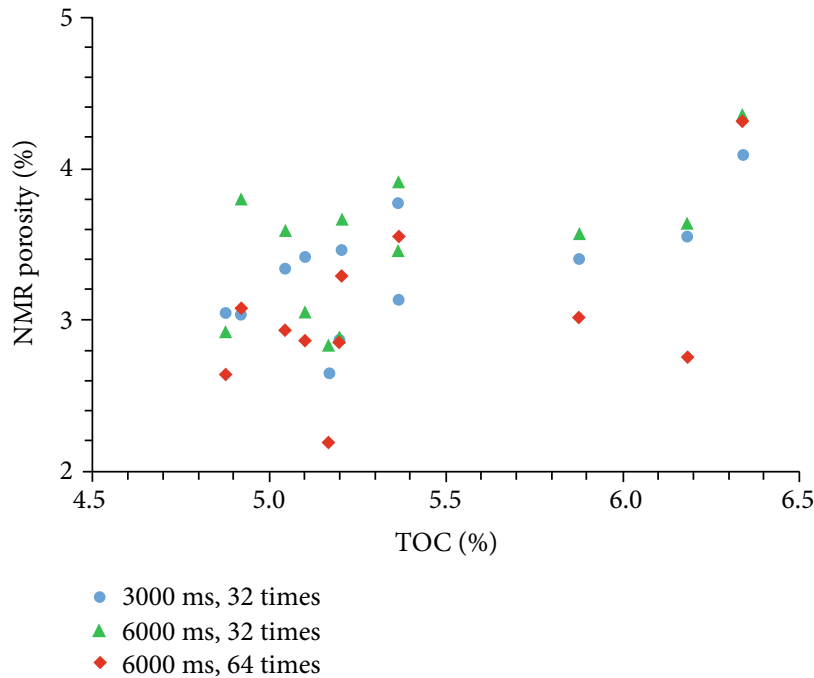

FIgURE 6: Porosities from NMR tests with different experimental parameters.

$6000 \mathrm{~ms}$ and 64 times, respectively, to assess the influence of experimental parameters on NMR porosity. An increase in measured porosity is shown in Figure 6 as a result of the increase in waiting time TW for a given sample. However, with the number of scans changed from 32 to 64 times, an unexpected decrease in NMR porosity shows up in Figure 6; this may be due to the increase in water loss from samples because of the nearly doubled experimental time. Thus, controls of temperature and humidity during the NMR measurements are critical, as are the experimental parameters.

4.2. Multifluid Impact on HP, WIP, and MIP Methods. The HP technique is a very common method for skeletal density measurements due to the smaller molecular size of helium compared with water or other fluids, and its inertness towards organic matter and inorganic matrices increases its ability to access more pores. However, no significant difference is shown between HP and WIP skeletal densities for the same sample size (Figure 3). It is possible that some small pores may not be accessed by helium since it is likely to be a nonwetting phase for the as-received shale samples, whereas the shale samples adsorb more water due to the existence of hydrophilic minerals and bound water.

Although two different fluids, DI water and mercury, were employed in WIP and MIP measurements, the skeletal densities of samples from two methods are generally comparable (Table 2; Figure 3). In MIP, the highest pressure was up to $60,000 \mathrm{psi}(413 \mathrm{MPa})$, which is much higher than the saturating pressure (15 MPa) applied in WIP. The higher vacuum used in MIP measurement $(50 \mu \mathrm{m} \mathrm{Hg}$ pressure or $6.7 \mathrm{~Pa})$, compared with that of WIP measurement $(200 \mathrm{~Pa})$, contributes to the invasion of mercury into evacuated pore space [22]. Compared with mercury, DI water experiences less resistance to small pores during the invasion due to the existence of hydrophilic minerals and pores.

Effective porosities from WIP tend to be significantly higher than those from MIP (Table 3; Figure 4). This can 


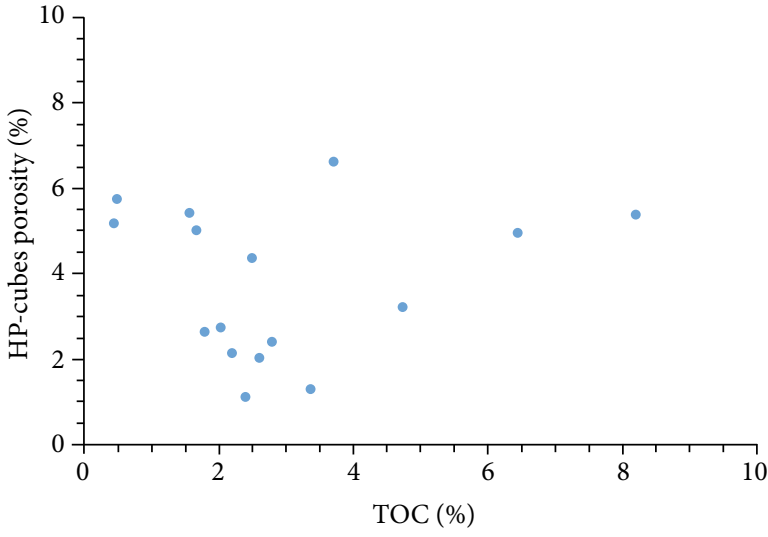

(a)

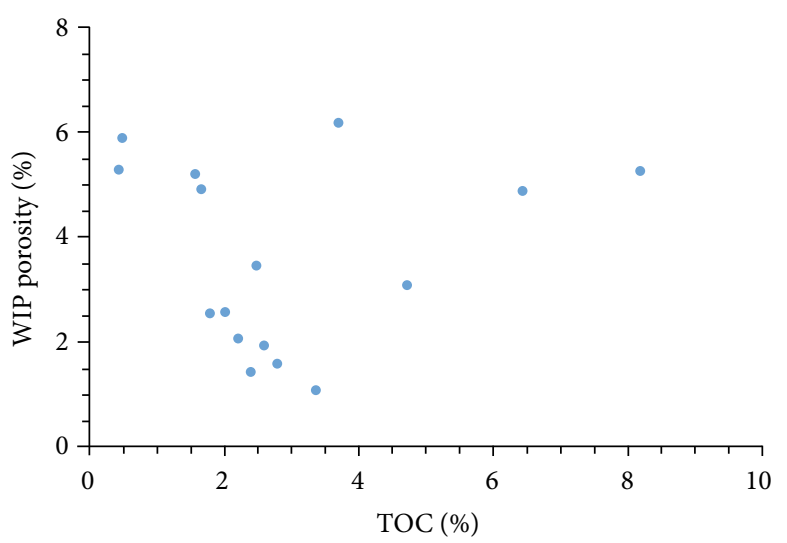

(c)

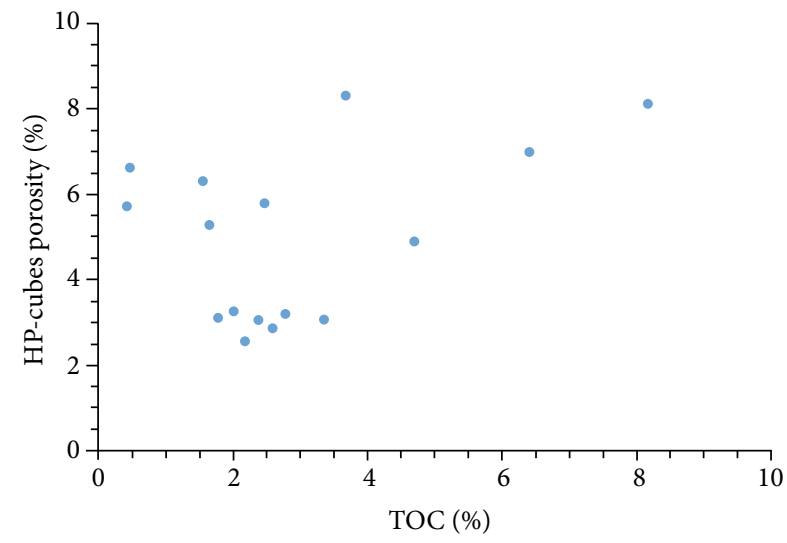

(b)

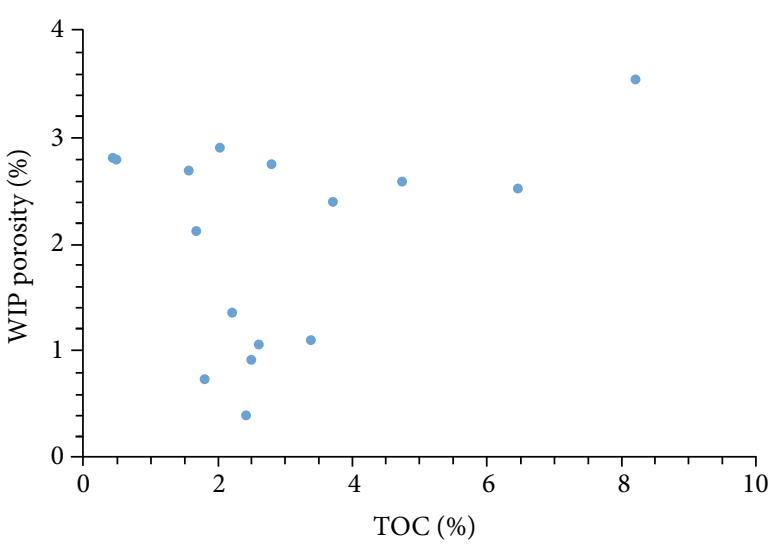

(d)

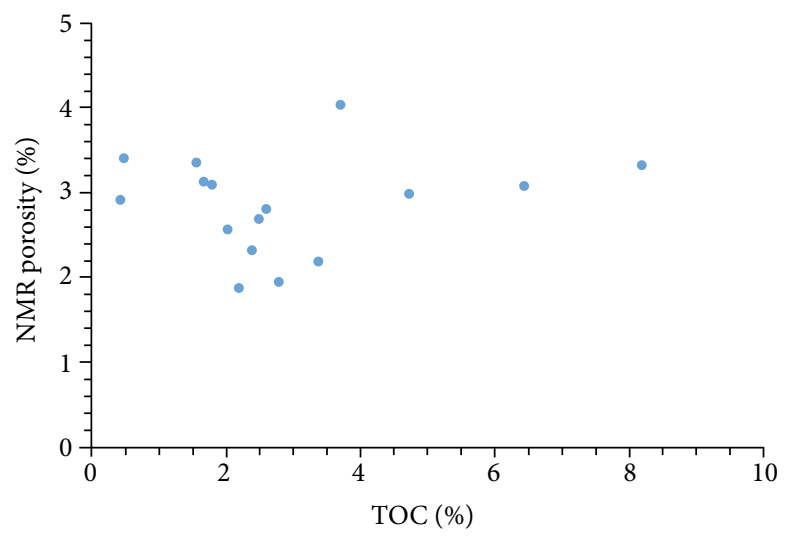

(e)

FIgURE 7: Relationships between TOC and porosities from different methods.

be attributed to undetected pore-throat diameter ranges larger than $50 \mu \mathrm{m}$ or smaller than $2.8 \mathrm{~nm}$ in MIP. In addition, sample compressibility and fractures induced under high pressures are potential factors in MIP measurements that would influence both effective porosity and skeletal density data [30, 31]. The size and structure of clay minerals might impact effective porosity and permeability analyses of tight shale, due to the potential plugging of pore channels $[54,55]$.

Comparisons of the skeletal density and effective porosity values calculated using HP measurement on granular sam- ples and WIP are shown in Figures 3 and 4. The reduced granular size systematically result in somewhat higher values of skeletal density and much higher values of porosity, because isolated pores in the larger samples are made accessible to the probing fluids when crushed to grains [37]; isolated pores are dominant in tight shale and the relative abundance is proportional to the sample size [36]. Thus, the HP porosity of granular samples at $500-841 \mu \mathrm{m}$ can be considered to be a good approximation of the "total" porosity, and the difference between HP and WIP porosities could indicate the extent of isolated porosity. 


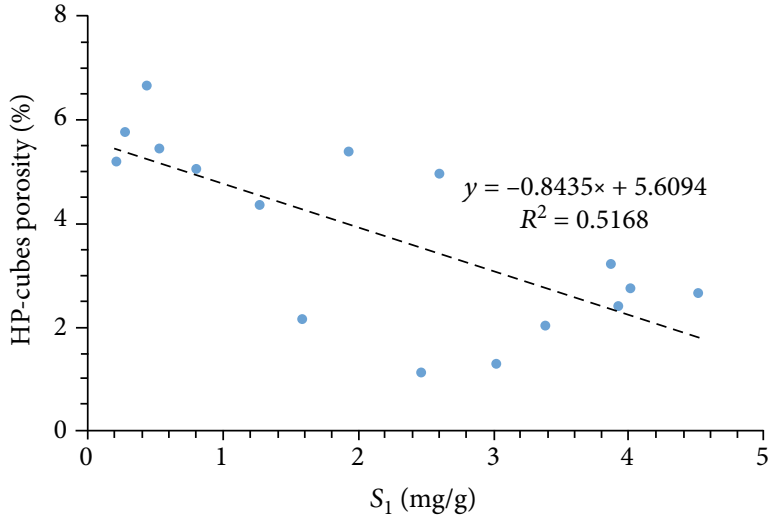

(a)

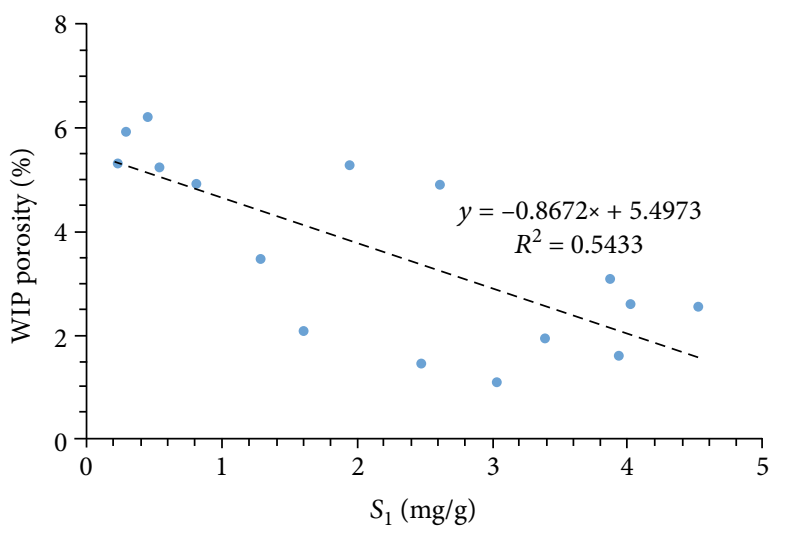

(c)

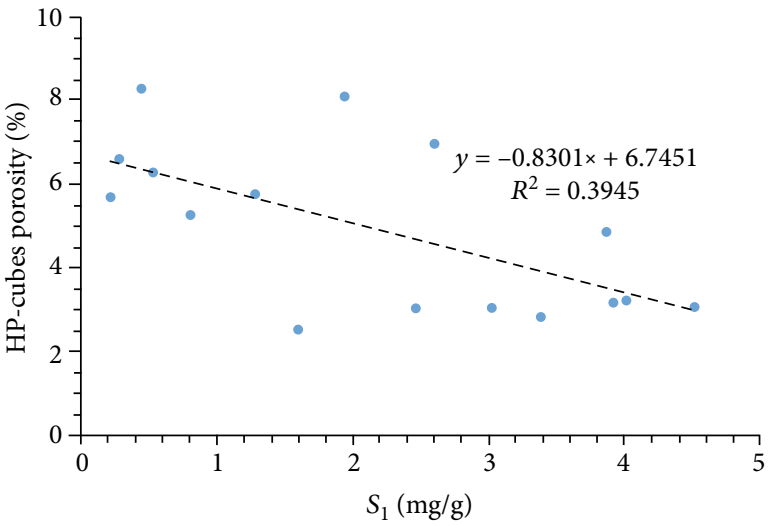

(b)

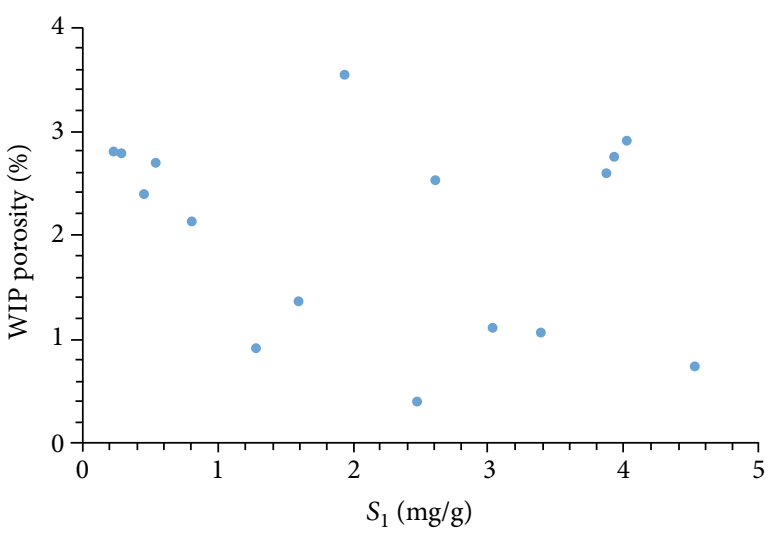

(d)

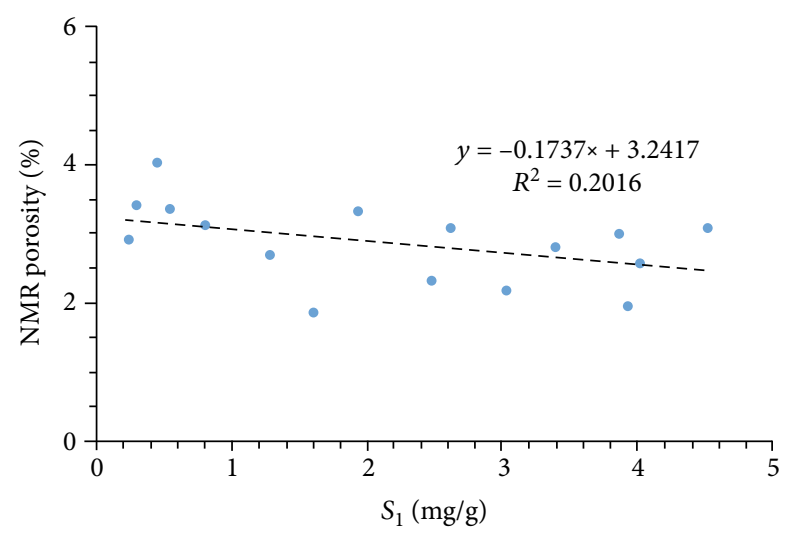

(e)

FIgURE 8: Relationships between $S_{1}$ and porosities from different methods.

4.3. Bulk Density Measurements Implicated by Clay Swelling. In this study, three methods (WIP, paraffin-sealing, and DryFlo $^{\circledR}$ envelopment) were used to measure the bulk density of samples (Section 3.2.1 and Table 2). The DryFlo method tended to give the highest densities, followed by WIP, then "sealed by paraffin" methods. A possible reason for the difference between the three methods could be the clay swelling ability of clay minerals, especially smectite and mixed-layered illite-smectite, during the saturation process with DI water. $\mathrm{Ek}_{2}$ shale reservoirs have oil window thermal maturities, with the majority of smectite already transformed to mixed-layered illite-smectite and illite $[39,40]$. Thus, the relative difference in bulk density from WIP and the other two methods is less than $2 \%$ (Table 2). In addition, there is no clear relationship between clay minerals and relative difference in porosity, suggesting a minor effect of clay swelling in our results. Generally, a slight swelling of $\mathrm{Ek}_{2}$ shale samples and the resulting experimental uncertainty is acceptable. In addition, a higher vacuum followed by a reduced time of saturation during the WIP tests could help to reduce the degree of sample swelling [21].

4.4. Effects of Organic Matter on Porosity Measurements. Abundant pores in organic matter could make a significant 
contribution to shale porosity, especially in gas shales at high thermal maturities [15]. In this work, no significant relationships are observed between TOC and effective porosities from HP, WIP, MIP, and NMR measurements. A very slight positive relationship between TOC and porosity of samples is shown in Figure 7, which suggests limited contributions of organic matter-hosted pore volumes to the porosity of samples.

Negative-to-no relationships between $S_{1}$ and porosities are shown in Figure 8, indicating that some pores might be occupied by bitumen and liquid hydrocarbons. Solvent extraction, which removes both liquid and solid (bitumen) hydrocarbons, has been shown to increase porosity in previous studies [56, 57]. In Figure 8(d), the complicated relationship between $S_{1}$ and MIP porosity may result from the residual hydrocarbons in pores pushed by mercury under high pressure to migrate at micro- to nanolevels [56].

\section{Conclusions}

In this study, sixteen lacustrine shale samples from $\mathrm{Ek}_{2}$ in Cangdong Sag in Bohai Bay Basin in East China were studied to quantify the effective porosity and bulk and skeletal densities using HP, WIP, MIP, and NMR techniques. The porosities measured by WIP and NMR methods are noticeably different, which may potentially result from moisture loss in pores during NMR measurement (heat-controlling approaches have been developed and implemented for follow-on studies) and countercurrent imbibition during the saturation process. In addition, the experimental parameters used in NMR need to be considered to detect total effective pores without an underestimation from signal losses.

A slight increase of skeletal density is observed for HP compared with that of WIP, because of a small molecular size of helium and imperfect wetting to water of the shale, while the deviation of MIP skeletal densities can be attributed to the experimental conditions (e.g., vacuum efficiency, applied pressure, and wettability of water/helium vs. mercury). Porosities of granular samples measured by HP are the highest among the four methods, because more isolated pores can start to be liberated in smaller granular sizes (i.e., 500$841 \mu \mathrm{m})$, and so this can be considered as close to the "total" porosity. The HP method is versatile in dealing with a range of sample sizes, and we are currently using it for independent measurements of both skeletal and bulk densities for a wide range of granular sizes (from $2.54 \mathrm{~cm}$ diameter core plugs down to $\sim 30 \mu \mathrm{m}$ granular samples) to identify when the "total porosity" is achieved. The difference between HP porosity of granular samples and WIP porosity of cubeshaped samples may indicate the extent of isolated porosity. Complementary approaches to quantifying the total (both effective/connected and nonconnected), such as SANS and FIB-SEM, are also ongoing.

Although clay swelling was suspected on $\mathrm{Ek}_{2}$ shale samples, its effect on results from WIP measurements is insignificant because of the low content of clay minerals, especially with clay types of predominantly mixed-layered illitesmectite with a partial expandability but only a modest amount of much more expandable smectite. Therefore,
WIP could be employed to measure the porosity of samples with low contents of expandable clay minerals, and the HP tests are suitable for total effective porosity measurements. Whereas the NMR and MIP methods are best suited for analyzing the pore-size distribution, as well as providing ancillary values of porosity. While relevant to subsurface conditions, the porosity measurements of as-received samples with high residual shale oil contents in this work may have restricted usage in assessing total porosity for resource evaluation, due to the partial blockage of residual oil during the measurement, as suggested by a weak negative relationship between $S_{1}$ and porosities. The work of solvent extraction on these samples with the follow-on porosity quantification is ongoing.

\section{Data Availability}

All laboratory data used to support the findings of this study are included within the article.

\section{Disclosure}

We would also like to declare that the work in this manuscript is an original research that has not been published previously or submitted to another journal.

\section{Conflicts of Interest}

The authors declare that they have no known competing financial interests or personal relationships that could have appeared to influence the work reported in this paper.

\section{Acknowledgments}

This work was funded by the National Natural Science Foundation of China (Nos. 41830431 and 41802146) and the Key Laboratory of Unconventional Petroleum Geology, China Geological Survey (No. 30200018-19-ZC0613-0065). The authors would like to thank Dagang Oilfield Company of China National Petroleum Corporation (CNPC) for providing the core samples used in this work.

\section{References}

[1] K. A. Bowker, "Barnett Shale gas production, Fort Worth Basin: issues and discussion," AAPG Bulletin, vol. 91, no. 4, pp. 523-533, 2007.

[2] R. G. Loucks and S. C. Ruppel, "Mississippian Barnett Shale: lithofacies and depositional setting of a deep-water shale-gas succession in the Fort Worth Basin, Texas," AAPG Bulletin, vol. 91, no. 4, pp. 579-601, 2007.

[3] C. R. Clarkson, J. L. Jensen, and S. Chipperfield, "Unconventional gas reservoir evaluation: what do we have to consider?," Journal of Natural Gas Science and Engineering, vol. 8, pp. 933, 2012.

[4] D. M. Jarvie, "Shale resource systems for oil and gas: part 2-shale-oil resource systems," AAPG Memoir, vol. 97, pp. 89-119, 2012.

[5] L. Chen, L. Zuo, Z. Jiang et al., "Mechanisms of shale gas adsorption: evidence from thermodynamics and kinetics study 
of methane adsorption on shale," Chemical Engineering Journal, vol. 361, pp. 559-570, 2019.

[6] R. Yang, Q. Hu, S. He et al., "Wettability and connectivity of overmature shales in the Fuling gas field, Sichuan Basin (China)," AAPG Bulletin, vol. 103, no. 3, pp. 653-689, 2019.

[7] Q. Hu, Y. Zhang, X. Meng, Z. Li, Z. Xie, and M. Li, "Characterization of micro-nano pore networks in shale oil reservoirs of Paleogene Shahejie Formation in Dongying Sag of Bohai Bay Basin, East China," Petroleum Exploration and Development, vol. 44, no. 5, pp. 720-730, 2017.

[8] B. Liu, J. Shi, X. Fu et al., "Petrological characteristics and shale oil enrichment of lacustrine fine-grained sedimentary system: a case study of organic-rich shale in first member of Cretaceous Qingshankou Formation in Gulong Sag, Songliao Basin, NE China," Petroleum Exploration and Development, vol. 45, no. 5, pp. 884-894, 2018.

[9] X. Tang, J. Zhang, X. Wang, B. Yu, W. Ding, and L. Zhang, "Geochemical characteristics and estimation of gas content of the low-middle mature continental shales: a case study from the Ordos Basin," 2013 AAPG Annual Convention and Exhibition, vol. 10517, p. 35, 2013.

[10] S. Zhang, C. Liu, H. Liang et al., "Paleoenvironmental conditions, organic matter accumulation, and unconventional hydrocarbon potential for the Permian Lucaogou Formation organic-rich rocks in Santanghu Basin, NW China," International Journal of Coal Geology, vol. 185, pp. 4460, 2018.

[11] B. Katz and F. Lin, "Lacustrine basin unconventional resource plays: key differences," Marine and Petroleum Geology, vol. 56, pp. 255-265, 2014.

[12] Y.-H. Sun, F.-T. Bai, X.-S. Lü et al., “A novel energy-efficient pyrolysis process: Self-pyrolysis of oil shale triggered by topochemical heat in a horizontal fixed bed," Scientific Reports, vol. 5, no. 1, p. 8290, 2015.

[13] W. Zhao, H. Suyun, L. Hou et al., "Types and resource potential of continental shale oil in China and its boundary with tight oil," Petroleum Exploration and Development, vol. 47, no. 1, pp. 1-11, 2020.

[14] D. L. Luffel and F. K. Guldry, "New core analysis methods for measuring reservoir rock properties of Devonian shale," Journal of Petroleum Technology, vol. 44, pp. 1184-1190, 2013.

[15] R. Yang, S. He, Q. Hu, D. Hu, S. Zhang, and J. Yi, "Pore characterization and methane sorption capacity of over-mature organic-rich Wufeng and Longmaxi shales in the southeast Sichuan Basin, China," Marine and Petroleum Geology, vol. 77, pp. 247-261, 2016.

[16] G. Wang, H. Yu, and B. De Man, "An outlook on X-ray CT research and development," Medical Physics, vol. 35, no. 3, pp. 1051-1064, 2008.

[17] X. Tang, Z. Jiang, S. Jiang, and Z. Li, “Heterogeneous nanoporosity of the Silurian Longmaxi Formation shale gas reservoir in the Sichuan Basin using the QEMSCAN, FIB-SEM, and nanoCT methods," Marine and Petroleum Geology, vol. 78, pp. 99109, 2016.

[18] Q. Hu, T. J. Kneafsey, R. C. Trautz, and J. S. Y. Wang, "Tracer penetration into welded tuff matrix from flowing fractures," Vadose Zone Journal, vol. 1, no. 1, pp. 102-112, 2002.

[19] Q. Hu, X. Gao, Z. Gao, R. Ewing, S. Dultz, and J. Kaufmann, "Pore accessibility and connectivity of mineral and kerogen phases in shales," Unconventional Resources Technology Conference, vol. 1922943, p. 17, 2014.
[20] U. Kuila, D. K. McCarty, A. Derkowski, T. B. Fischer, and M. Prasad, "Total porosity measurement in gas shales by the water immersion porosimetry (WIP) method," Fuel, vol. 117, pp. 1115-1129, 2014.

[21] T. Topór, A. Derkowski, U. Kuila, T. B. Fischer, and D. K. McCarty, "Dual liquid porosimetry:a porosity measurement technique for oil- and gas-bearing shales," Fuel, vol. 183, pp. 537-549, 2016.

[22] M. G. Kibria, Q. Hu, H. Liu, Y. Zhang, and J. Kang, "Pore structure, wettability, and spontaneous imbibition of Woodford Shale, Permian Basin, West Texas," Marine and Petroleum Geology, vol. 91, pp. 735-748, 2018.

[23] M. Sun, B. Yu, Q. Hu et al., "Pore structure characterization of organic-rich Niutitang shale from China: Small angle neutron scattering (SANS) study," International Journal of Coal Geology, vol. 186, pp. 115-125, 2018.

[24] J. Li, S. Lu, G. Chen, M. Wang, S. Tian, and Z. Guo, "A new method for measuring shale porosity with low-field nuclear magnetic resonance considering non-fluid signals," Marine and Petroleum Geology, vol. 102, pp. 535-543, 2019.

[25] Y. Zhang, Q. Hu, S. Long et al., "Mineral-controlled nm- $\mu \mathrm{m}$ scale pore structure of saline lacustrine shale in Qianjiang Depression, Jianghan Basin, China," Marine and Petroleum Geology, vol. 99, pp. 347-354, 2019.

[26] IUPAC, "Manual of symbols and terminology," Pure and Applied Chemistry, vol. 31, p. 578, 1972.

[27] M. J. Wilson, M. V. Shaldybin, and L. Wilson, "Clay mineralogy and unconventional hydrocarbon shale reservoirs in the USA. I. Occurrence and interpretation of mixed-layer R3 ordered illite/smectite," Earth-Science Reviews, vol. 158, pp. 31-50, 2016.

[28] E. W. Washburn, "Note on a method of determining the distribution of pore sizes in a porous material," Proceedings of the National Academy of Sciences of the United States of America, vol. 7, no. 4, pp. 115-116, 1921.

[29] A. J. Katz and A. H. Thompson, "Quantitative prediction of permeability in porous rock," Physical Review B, vol. 34, no. 11, pp. 8179-8181, 1986.

[30] Z. Gao and Q. Hu, "Estimating permeability using median pore-throat radius obtained from mercury intrusion porosimetry," Journal of Geophysics and Engineering, vol. 10, no. 2, article 025014, 2013.

[31] H. Giesche, "Mercury porosimetry: a general (practical) overview," Particle and Particle Systems Characterization, vol. 23, no. 1, pp. 9-19, 2006.

[32] R. F. Sigal, "A methodology for blank and conformance corrections for high pressure mercury porosimetry," Measurement Science and Technology, vol. 20, no. 4, article 045108, 2009.

[33] G. Coates, L. Xiao, and M. Prammer, "NMR logging: principles and applications," Haliburton Energy Services, vol. 234, 1999.

[34] N. Bloembergen, E. M. Purcell, and R. V. Pound, "Relaxation effects in nuclear magnetic resonance absorption," Physical Review, vol. 73, no. 7, pp. 679-712, 1948.

[35] E. Rylander, P. M. Singer, T. Jiang, R. Lewis, R. McLin, and S. Sinclair, "NMR T2 distributions in the Eagle Ford shale: reflections on pore size," SPE USA Unconventional Resources Conference 2013, pp. 426-440, 2013.

[36] Q. Hu, "Quantifying effective porosity of oil and gas reservoirs," AAPG Search and Discovery Article, vol. 70376, 2018.

[37] J. T. Comisky, M. Santiago, B. McCollom, A. Buddhala, and K. E. Newsham, "Sample size effects on the application of 
mercury injection capillary pressure for determining the storage capacity of tight gas and oil shales," Society of Petroleum Engineers - Canadian Unconventional Resources Conference 2011, pp. 2103-2125, 2011.

[38] J. Sun, X. Dong, J. Wang et al., "Measurement of total porosity for gas shales by gas injection porosimetry (GIP) method," Fuel, vol. 186, pp. 694-707, 2016.

[39] X. Zhao, L. Zhou, X. Pu et al., "Development and exploration practice of the concept of hydrocarbon accumulation in rifted-basin troughs: A case study of Paleogene Kongdian Formation in Cangdong sag, Bohai Bay Basin," Petroleum Exploration and Development, vol. 45, no. 6, pp. 1166-1176, 2018.

[40] X. Pu, L. Zhou, W. Han et al., "Geologic features of finegrained facies sedimentation and tight oil exploration: a case from the second Member of Paleogene Kongdian Formation of Cangdong Sag, Bohai Bay Basin," Petroleum Exploration and Development, vol. 43, no. 1, pp. 24-33, 2016.

[41] K. Chen, X. Liu, J. Liu, C. Zhang, M. Guan, and S. Zhou, "Lithofacies and pore characterization of continental shale in the second Member of the Kongdian Formation in the Cangdong Sag, Bohai Bay Basin, China," Journal of Petroleum Science and Engineering, vol. 177, pp. 154-166, 2019.

[42] F. Behar, V. Beaumont, B. Penteado, and H. De, "Rock-Eval 6 technology: Performances and developments," Oil \& Gas Science and Technology, vol. 56, no. 2, pp. 111-134, 2001.

[43] L. E. Flint, "Characterization of hydrogeologic units using matrix properties, Yucca Mountain, Nevada," WaterResources Investigations Report, vol. 98, p. 4243, 1998.

[44] W. M. Haynes, D. R. Lide, and T. Bruno, CRC Handbook of Chemistry and Physics 2012-2013, vol. 93, pp. 7-9, 2012.

[45] N. Zhang, M. He, B. Zhang, F. Qiao, H. Sheng, and Q. Hu, "Pore structure characteristics and permeability of deep sedimentary rocks determined by mercury intrusion porosimetry," Journal of Earth Science, vol. 27, no. 4, pp. 670-676, 2016.

[46] S. Wang, F. Javadpour, and Q. Feng, "Confinement correction to mercury intrusion capillary pressure of shale nanopores," Scientific Reports, vol. 6, 2016.

[47] H. Tian, L. Pan, X. Xiao, R. W. T. Wilkins, Z. Meng, and B. Huang, "A preliminary study on the pore characterization of Lower Silurian black shales in the Chuandong Thrust Fold Belt, southwestern China using low pressure $\mathrm{N}_{2}$ adsorption and FE-SEM methods," Marine and Petroleum Geology, vol. 48, pp. 8-19, 2013

[48] F. Rabier, M. Temmerman, T. Böhm et al., "Particle density determination of pellets and briquettes," Biomass and Bioenergy, vol. 30, no. 11, pp. 954-963, 2006.

[49] M. Q. Hu, P. Persoff, and J. S. Y. Wang, "Laboratory measurement of water imbibition into low-permeability welded tuff," Journal of Hydrology, vol. 242, no. 1-2, pp. 64-78, 2001.

[50] M. Meng, H. Ge, W. Ji, Y. Shen, and S. Su, "Monitor the process of shale spontaneous imbibition in co-current and counter-current displacing gas by using low field nuclear magnetic resonance method," Journal of Natural Gas Science and Engineering, vol. 27, pp. 336-345, 2015.

[51] Q. Meng, Z. Cai, J. Cai, and F. Yang, "Oil recovery by spontaneous imbibition from partially water-covered matrix blocks with different boundary conditions," Journal of Petroleum Science and Engineering, vol. 172, pp. 454-464, 2019.

[52] X. Liu, Q. Liu, J. Liu, Q. Dong, M. Guan, and H. Li, “Geochemical characteristics of organic-rich shales of the second Member of Kongdian Formation in Cangdong Sag, Huanghua
Depression," Lithologic Reservoirs, vol. 27, no. 6, pp. 15-22, 2015.

[53] L. L. Handy, "Determination of effective capillary pressures for porous media from imbibition data," Transactions of the AIME, vol. 219, no. 1, pp. 75-80, 2013.

[54] D. Xiao, S. Jiang, D. Thul, S. Lu, L. Zhang, and B. Li, "Impacts of clay on pore structure, storage and percolation of tight sandstones from the Songliao Basin, China: implications for genetic classification of tight sandstone reservoirs," Fuel, vol. 211, pp. 390-404, 2018.

[55] R. Wang, W. Shi, X. Xie et al., "Clay mineral content, type, and their effects on pore throat structure and reservoir properties: insight from the Permian tight sandstones in the Hanginqi area, north Ordos Basin, China," Marine and Petroleum Geology, vol. 115, p. 104281, 2020.

[56] J. J. Valenza, N. Drenzek, F. Marques, M. Pagels, and M. Mastalerz, "Geochemical controls on shale microstructure," Geology, vol. 41, no. 5, pp. 611-614, 2013.

[57] L. Chen, Z. Jiang, Q. Liu et al., "Mechanism of shale gas occurrence: insights from comparative study on pore structures of marine and lacustrine shales," Marine and Petroleum Geology, vol. 104, pp. 200-216, 2019. 